\title{
PERAN TAMAN BACA MASYARAKAT SILAYUNG DALAM MENINGKATKAN LITERASI INFORMASI
}

\author{
Fatur Prahardika \\ IKIP Siliwangi, Cimahi, Jawa Barat, Indonesia \\ faturprahardika@gmail.com
}

Received: Desember 2019 ; Accepted: Januari 2020

\begin{abstract}
The ability of the community and knowledge become more developed after the presence of communication and information technology. Information literacy can also be termed as 'information literacy, even in various scientific meetings / forums it is often discussed about this information literacy. Information literacy can also be interpreted as a series of skills for finding, receiving, processing, and utilizing information to others to complete and find a solution, therefore information literacy is needed because of the rapid advances in technology today. Diverse information among the people today causes people to need expertise, one of which is expertise about information. The amount of information available makes the searchers and users of information confused to get relevant information. A method is needed to find information from various sources of information that are developing. Literacy can help to find the information needed quickly, easily and relevant. This study uses a qualitative descriptive approach, meaning that the data collected is not in the form of numbers, but the data comes from interview scripts, field notes, personal documents, memo notes, and other official documents. The purpose of this study is to determine the Silayung TBM management process in improving information literacy.

Keywords: Information Literacy, TBM Silayung
\end{abstract}

\begin{abstract}
ABSTRAK
Kemampuan masyarakat serta pengetahuan menjadi semakin berkembang setelah kehadirannya teknologi komunikasi dan informasi. Literasi informasi dapat di istilahkan juga dengan istilah 'melek informasi, bahkan diberbagai pertemuan/forum ilmiah juga sering didiskusikan mengenai literasi informasi ini. Literasi informasi juga dapat diartikan sebagai serangkaian keterampilan untuk mencari, menerima, mengolah, dan memanfaatkan informasi kepada orang lain untuk menyelesaikan dan mencari jalan keluarnya, maka dari itu literasi informasi sangat dibutuhkan karena pesatnya kemajuan teknologi saat ini. Informasi yang beragam dikalangan masyarakat saat ini menyebabkanmasyarakat memerlukan keahlian, salah satunya keahlian yaitu tentang informasi. Banyaknya informasi yang tersedia membuat pencari dan pengguna informasi kebingungan untuk mendapatkan informasi yang relevan. Diperlukan sebuah metode untuk mencari informasi dari berbagai sumber informasi yang berkembang. Literasi dapat membantu untuk menemukan informasi yang dibutuhkan secara cepat, mudah dan relevan.Penelitian ini menggunakan pendekatan deskriptif kualitatif, artinya data yang dikumpulkan bukan berupa angka-angka, melainkan data tersebut berasal dari naskah wawancara, catatan lapangan, dokumen pribadi, catatan memo, dan dokumen resmi lainnya. Tujuan penelitian ini yaitu untuk mengetahui proses pengelolaan TBM Silayung dalam meningkatkan Literasi informasi.
\end{abstract}

Kata Kunci:,Literasi Informasi, TBM Silayung

How to Cite: Prahardika, F. (2020). Peran Taman Baca Masyarakat Silayung Dalam Meningkatkan Literasi Informasi. Comm-Edu (Community Education Journal) 3 (1), 50-55. 


\section{PENDAHULUAN}

Perkembangan kehidupan masyarakat serta pengetahuan menjadi semakin berkembang dengan kehadiran teknologi komunikasi dan informasi. Semakin berkembangnya teknologi di bidang informasi pada saat ini, menyebabkan semakin pesatnya informasi yang didapat oleh masyarakat. Informasi yang didapat oleh masyarakat bisa berupa dokumen, berita, laporan, dan lain-lain. Informasi telah menjadi komoditi yang paling penting dalam era informasi saat ini. Perkembangan teknologi informasi saat ini yang nyata adalah perkembangan internet yang merupakan jaringan global. Akhir-akhir ini kita sering mendengar istilah literasi informasi. Literasi informasi dapat di istilahkan juga dengan istilah 'melek informasi'. Bahkan di berbagai pertemuan/forum ilmiah juga sering didiskusikan mengenai literasi informasi ini. Literasi informasi juga dapat diartikan sebagai serangkaian keterampilan untuk mencari, menerima, mengolah, dan memanfaatkan informasi kepada orang lain umtuk menyelsaikan dan mencari jalan keluarnya.

Kemampuan literasi informasi sangat penting karena pesatnya kemajuan teknologi. Informasi yang beragam menyebabkan menyebabkan masyarakat memerlukan keahlian ini. Banyaknya informasi yang tersedia membuat pencari dan pengguna informasi kebingungan untuk mendapatkan informasi yang relevan. Diperlukan sebuah metode untuk mencari informasi dari berbagai sumber informasi yang berkembang. Literasi dapat membantu untuk menemukan informasi yang dibutuhkan secara cepat, mudah dan relevan. Dengan literasi, masyarakat dapat memilih dan memilah informasi mana yang benar dan meragukan atau tidak benar dengan informasi yang sedang berkembang saat ini.

Perkembangan pengguna internet di Indonesia menurut (APJII, 2019), yang melakukan survei pengguna internet di Indonesia. Hasilnya, pengguna internet di Indonesia bertambah sebesar 10,12 persen pada 2018 dibandingkan tahun sebelumnya. Secara keseluruhan, pengguna internet di Indonesia mencapai 171,17 juta pengguna dari populasi 264,16 juta jiwa. Dari 171,17 juta pengguna internet 2018, Pulau Jawa masih memberikan kontribusi paling besar terhadap peningkatan jumlah pengguna internet di Indonesia . Karena 55 persen pengguna internet berada di Pulau Jawa. Selanjutnya disusul Pulau Sumatera dengan 21persen, Sulawesi-Maluku-Papua (10 persen), Kalimantan (9 persen), dan Bali-Nusa Tenggara sebesar (5 persen). APJII juga membagi kontribusi pengguna internet per provinsi. Hasil survei tersebut menunjukkan, di Pulau Jawa, Jawa Barat adalah provinsi yang memberikan kontribusi pengguna internet tertinggi. Sedangkan Jawa Tengah dan Jawa Timur kontribusinya 16,6 persen.Untuk Sumatera, Sumatera Utara menjadi penyumbang terbesar pengguna internet dengan persentase sebesar 6,3 persen, tertinggi dibandingkan provinsi lainnya. Sementara Provinsi Kalimantan Barat memegang andil terbesar dengan kontribusi 2,1 persen. Lalu, untuk Sulawesi-Maluku-Papua, Sulawesi Selatan punya kontribusi terbesar, yakni 3,7 persen.

Maka dengan pesatnya perkembangan penggunaan internet sebagai salah satu carauntuk mendapatkan informasi di masyarakat perlu adanya salah satu wadah atau tempat untuk membantu mengarahkan masyarakat agar bisa menggunakan literasi informasi dengan bijak, salah satu program Pendidikan Luar Sekolah (PLS) yang bisa memfasilitasi masyarakat itu adalah Taman Bacaan Masyarakat (TBM). Taman Bacaan Masyarakat (TBM) adalah salah satu program pemerintah yang mengacu pada (Depdiknas, 2003)Undang-Undang Republik Indonesia No. 20 tahun 2003 tentang Sistem Pendidikan Nasional, pasal 26 ayat (4), tercantum bahwa satuan pendidikan non-formal terdiri atas lembaga kursus dan pelatihan(LKP), kelompok belajar, pusat kegiatan belajar masyarakat(PKBM), majelis 

Informasi

taklim, dan satuan pendidikan yang sejenis. Dengan adanya Taman Baca Masyarakat (TBM) diharapkan dapat membantu masyarakat meningkatkan kemampuan dan menambah wawasan tentang membaca, menulis dan informasi.Jadi, keberaksaraan atau literasi dapat diartikan sebagai melek teknologi, melek informasi, berpikir kritis, peka terhadap lingkungan, bahkan juga peka terhadap politik. Seorang dikatakan literat jika ia sudah bisa memahami sesuatu karena membaca informasi yang tepat dan melakukan sesuatu berdasarkan pemahamannya terhadap isi bacaan tersebut. Literasi pada seseorang tentu tidak muncul begitu saja. Tidak ada manusia yang sudah literat sejak lahir tanpa memahami apa itu literasi. Menciptakan generasi literat membutuhkan prosesyang panjang dan sarana yang kondusif. Proses ini dimulai dari hal kecil dan dari ruang lingkup keluarga, lalu didukung dan dikembangkan di sekolah, lingkungan pergaulan, dan lingkungan pekerjaan.

\section{LANDASAN TEORI}

\section{Taman Bacaan Masyarakat}

Taman Bacaan Masyarakat adalah sebuah lembaga yang meyediakan perkembangan budaya membaca serta kemamuan membaca masyarakat, TBM menyediakan fasilitas membaca serta fasilitas lain yang bertujuan sebagai sumber informasi untuk masyarakat (Depdikbud, 2009).

Menurut Sutarno NS (Rahayu \& Widiastuti, 2018)Taman Bacaan Masyarakat (TBM) adalah tempat dibuat pemerintah, peroranganm atau swakelola dan swadaya masyarakat yang menyediakan bahan bacaan untuk menumbuhkan minat baca kepada masyarakat yang berada di sekitar Taman Bacaan Masyarakat (TBM).

TBM memiliki peran yang sangat penting untuk memberikan alternative pelayanan pendidikan serta menumbuhkan tradisi atau budaya membaca masyarakat. Menurut Lestari dan Susilo dalam jurnal Pendidikan Non Formal (PNF), peran TBM ada empat yaitu :

a. TBM merupakan sarana meningkatkan minat baca masyarakat dengan ruang dan bahan yang disediakan untuk membedah buku, membaca, diskusi, menulis, dan kegiatan lainnya.

b. TBM sebagai bagian penting pendidikan masyarakat dengan bacaan yang disediakan diharapkan bisa memotivasi dan menumbuhkan minat serta kegemaran membaca bagi aksarawan baru, warga belajar, dan masyarakat.

c. TBM merupakan sebuah tempat yang didirikan atau dikelola oleh masyarakat maupun pemerintah sebagai sarana pembelajaran hidup dalam rangka peningkatan kemampuan dan kualitas hidup masyarakat.

d. TBM juga memfasilitasi dan membangun suasana belajar di masyarakat sehingga mencari kesadaran kritis dalam menyikapi perkembangan lingkungan.

\section{Literasi Informasi}

Literasi informasi menurut Harras (Suwandi, 2019) dapat diartikan sebagai serangkaian keterampilan untuk mengidentifikasi, menemukan, mengevaluasi, menyusun, menciptakan, menggunakan dan mengkomunikasikan informasi kepada orang lain untuk menyelesaikan dan mencari jalan keluar dari suatu masalah.

Literasi informasi Menurut Bahtar dan Soedarsono (Suwanto, 2015) literasi informasi dapat diterjemahkan menjadi melek informasi, atau ada yang menyebutnya sebagai keberinformasian.

Dari definisi diatas dapat diambil kesimpulan bahwa literasi iformasi yaitu kemampuan seseorang dalam menemukan informasi, yang meliputi kesadaran seseorang dalam 
menggunakan, membutuhkan serta menemukan informasi tersebut agar dapat dikomunikasikan kepada lingkungan sekitar dengan jelas dan bermanfaat.

Sedangkan menurut Chan (2001) fungsi dari literasi informasi sebagai berikut:

1. Literasi informasi sangat penting untuk kesuksesan belajar seumur hidup.

2. Literasi informasi merupakan bagian penting dalam era informasi.

3. Literasi informasi memberi kontribusi pada perkembangan pengajaran dan pembelajaran.

\section{METODE}

Metode yang digunakan dalam penelitian ini adalah metode deskriptif dengan pendekatan. Menurut (Sugiyono, Metode Penelitian Kuantitatif Kualitatif dan R\&D, 2014) metode penelitian yang berlandaskan pada fisafat post positivisme, yang digunakan untuk meneliti pada objek yang alamiah, (sebagai lawannya adalah eksperimen) dimana peneliti adalah sebagai instrument kunci. Dengan kata lain data yang dikumpulkan bukan hanya berupa angka-angka saja, melainkan data tersebut dihasilkan dari naskah wawancara, catatan lapangan, dokumen pribadi, catatan memo, ataupun dokumen resmi lainnya. Oleh karena itu, tujuan penelitian yang menggambarkan realita empiris di balik fenomena secara mendalam, rinci dan tuntas dapat tercapai. Penelitian dilakukan di TBM SilayungDesa Ciburuy Kecamatan Padalarang merupakan salah satu Taman Baca Masyarakat (TBM) di Kabupaten Bandung Barat. Data penelitian didapat dari subjek penelitian yang menjadi sumber informasi yang terdiri dari satu orang pengelola, duaorang relawan, dan satu orang masyarakat sekitar. Tahap yang dilakukan utnuk pengumpulan data itu sendiri ada tiga tahap, yaitu tahap orientasi, eksplorasi, dan member chek. Teknik pengumpulan data menggunakan wawancara dan observasi. dalam bentuk instrumen tes mencakup tes tulis. Adapun teknik analisis data mencakup reduksi data, data display dan data kesimpulan/verifikasi.

\section{HASIL DAN PEMBAHASAN}

Hasil

Berdasarkan hasil penelitian di lapangan, maka peneliti akan memaparkan hasil wawancara peneliti dengan pengelola TBM Silayungdengan wawancara dilakukan selama beberapa pertemuan bersama HS (inisial), namun tidak hanya bersama pengelola saja melakukan wawancara melaikan bersama relawan dan masyarakat sekitar TBM Silayung dapat disimpulkan sebagai berikut:

Program yang dilaksanakan di TBM Silayung yaitu mulai dari membaca, menulis, dan berhitung (CALISTUNG), Bimbingan Belajar (BIMBEL), meningkatkan kreatifitas masyarakat, serta yang terdekat akan dilaksanakan, yaitu positif internet. Untuk saat ini TBM Silayung baru dalam tahap perencanaan, namun dalam waktu dekat TBM Silayung akan melaksanakan program literasi informasi, yaitu dengan melaksanakan kegiatan positif internet bersama dengan masyarakat sekitar TBM Silayung.Alasan utama TBM Silayung ingin melaksanakan program literasi informasi, yaitu karena masyarakat sekitar TBM Silayung masih kurangnya pemahaman tentang informasi itu sendiri khususnya dalam menggunakan media internet.Untuk saat ini masih dalam perencanaan namun dalam waktu dekat program literasi informasi di TBM Silayungakan dilaksanakan setiap satu pekan sekalidi TBM Silayung dengan melibatkan para pengelola dan para relawan yang ada di Taman Bacaan Masyarakat (TBM) dengan merancang kegiatan positif internet.

Selanjutnya HS menjelaskan mengenai tujuan, cara serta bagaimana respon terhadap TBM ini. Berikut hasil wawancara sebagai berikut: 

Informasi

Tujuan TBM Silayung merancang dan akan melaksanakan program literasi informasi, yaitu untuk menyampaikan tentang pentingnya media internet akan tetapi lebih menekankan tentang manfaat serta kegunaan yang lainnya.Yang terlebih dahulu para pengelola serta relawan mengidentifikasi dilapangan, selanjutnya hasil dari identifikasi tersebut menghasilkan/menentukan program apa yang akan dilaksanakan, rancangan program, pentuan jadwal, pelakanaan, serta evaluasi.Yang dilibatkan dalam merencanakan program di TBM Silayung mulai dari pengelola sampai dengan relawan.Sampai saat ini respon masyarakat sekitar di TBM Silayung sangat baik dan mendukung akan dilaksanakannya program literasi informasi.

\section{Pembahasan}

Hasil wawancara peneliti dengan pengelola dan relawanTBM Silayung mengenai peran TBMSilayung dalam meningkatkan literasi informasi, yaitu proses program literasi di TBM Silayung akan dilaksanakan sebagai salah satu cara meningkatkan literasi informasi dikalangan masyarakat sekitar TBM Silayung melalui program-program yang diberikan walaupun program yang diberikan masih belum menyeluruh serta masih harus dilakukan inovasi yang terbaru. Sesuai dengan teori menurut (UNESCO, 2008), juga menyatakan bahwa literasi informasi adalah kemampuan seseorang untuk:

1. Menyadari kebutuhan informasi,

2. Menemukan dan mengevaluasi kualitas informasi yang didapatkan,

3. Menyimpan dan menemukan kembali informasi yang diperoleh,

4. Membuat dan menggunakan informasi secara etis dan efektif,

5. Mengomunikasikan pengetahuan.

Dari uraian diatas literasi informasi sangat berhubungan dengan kemampuan berpikir kritis dari seemua informasi yang didapatkan serta kepekaan terhadap semua aspek kehidupan, literasi informasi menuntut kemampuan menganalisis suatu informasi untuk digunakan secara tepat untuk memecahkan masalah.Selain menjalankan program-program yang berhubungan dengan literasi informasi atau mengembangkan literasi informasi untuk meningkatkan kemampuan masayarakat, TBM Silayung juga sudah menjalankan peranan secara umum sebagai TBM yang sangat penting dalam menyiarkan pentingnya pendidikan alternatif serta menumbuhkan tradisi atau budaya membaca sekaligus sebagai tempat untuk mendapatkan informasi masyarakat.

Selain itu, respon pembaca juga sangat baik terhadap program-program yang dilaksanakan oleh pengelola sebagai salah satu cara pengelola dalam meningkatkan literasi informasi dikalangan masyarakat. Program-program tersebut menjadi salah satu tujuan pengelola dalam mendirikan TBM sebagai salah satu lembaga yang bertujuan memberikan kemudahan kepada masyarakat untuk mendapatkan akses informasi dan bahan bacaan. Sesuai pendapat Departemen Pendidikan Nasional (dalam Suwanto, 2015) bahwa TBM ditujukan untuk memperluas akses dalam memberikan kesempatan kepada masyarakat dalam mendapatkan layanan pendidikan.

\section{KESIMPULAN}

Dari penelitian diatas dapat disimpulkan bahwa literasi informasi sangat penting untuk kehidupan seseorang karena literasi informasi sangat berpengaruh di era saat ini, untuk itu seseorang harus memahami tentang literasi informasi agar bisa bersaing di era saat ini. Banyak masyarakat di Indonesia yang masih belum benar-benar memahami apa itu literasi informasi karena rendahnya keinginan untuk mencari tahu tentang pemahaman literasi informasisendiri. Akibatnya masyarakat Indonesia masih banyak yang belum paham 
bagaimana mencari, menemukan, mengelola dan mengaplikasikan suatu informasi dengan baik dan benar. Seseorang dapat dikatakan paham akan literasi informasi ketika dia bisa mencari, menerima, mengelola, dan mengaplikasikan suatu informasi itu dengan tepat. Upaya yang dilakukan TBM Silayung dalam meningkatkan literasi informasi masih dalam tahap perencanaan tetapi dalam waktu dekat para pengelola dan relawan TBM Silayung akan melaksanakan program literasi informasi berupa kegiatan positif internet. Alasan TBM Silayung merancang dan akan melaksanakan program literasi informasi, yaitu dikarenakan masyarakat disekitar TBM Silayung belum paham akan literasi informasi. Maka dari itu TBM Silayung beserta relawan yang ada disana berinisiatif untuk mengadakan program literasi informasi untuk masyarakat sekitar TBM Silayung. Para pengelola dan relawan berharap dengan adanya program literasi informasi dapat lebih memahami media internet.

\section{DAFTAR PUSTAKA}

APJII, S. (2019). Buletin APJII. Jakarta : APJII (Asosiasi Penyelenggara Jasa Internet Indonesia).

Chan, Y. C. (2001). Rethinkhing Information Literacy. A Study of Hongkong University Students, 1.

Depdiknas. (2003). Undang-Undang Republik Indonesia No. 20 tahun 2003. Jakarta: Sistem Pendidikan Nasional.

Rahayu, R., \& Widiastuti, N. (2018). Upaya Pengelola Taman Bacaan Masyarakat Dalam Memperkuat Minat Baca (Studi Kasus TBM Silayung Desa Ciburuy Kecamatan Padalarang). Jurnal Comm Edu 1(2), 57-65.

Sugiyono. (2014). Metode Penelitian Kuantitatif Kualitatif dan R\&D. Candung: Alfabeta.

Suwandi, S. (2019). Pendidikan Literasi. Bandung: PT. Remaja Rosdakarya Offset.

Suwanto, S. A. (2015). Analisis Literasi Informasi Pemakai Taman Bacaan Masyarakat. Jurnal Kajian Informasi \& Perpustakaan Vol.3/No.1 , 89-100. 